\section{6 OPEN ACCESS}

\title{
Smoking and overweight determine the likelihood of developing rheumatoid arthritis
}

\author{
Maria J H de Hair, ${ }^{1}$ Robert B M Landewé, ${ }^{1,2}$ Marleen G H van de Sande, ${ }^{1}$ \\ Dirkjan van Schaardenburg, ${ }^{3}$ Lisa G M van Baarsen, ${ }^{1}$ Danielle M Gerlag, ${ }^{1}$ Paul P Tak ${ }^{1}$
}

Handling editor Tore K Kvien

- Additional supplementary files are published online only. To view these files please visit the journal online (http://dx. doi.org/10.1136/annrheumdis2012-202254).

${ }^{1}$ Division of Clinical Immunology and Rheumatology, Academic Medical Center, University of Amsterdam, Amsterdam, The Netherlands ${ }^{2}$ Department of Rheumatology, Atrium Medical Center, Heerlen, The Netherlands ${ }^{3}$ Department of Rheumatology, Jan van Breemen Research Institute/Reade, Amsterdam, The Netherlands

\section{Correspondence to} Dr Danielle M Gerlag, Division of Clinical Immunology and Rheumatology, Academic Medical Center/University of Amsterdam, Meibergdreef 9, Amsterdam 1105 AZ, The Netherlands; d.m.gerlag@amc.uva.nl

Accepted 6 October 2012 Published Online First 27 October 2012

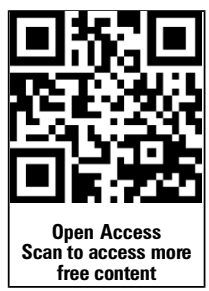

To cite: de Hair MJH, Landewé RBM, van de Sande MGH, et al. Ann Rheum Dis 2013;72. 1654-1658.

\section{ABSTRACT}

Objectives Rheumatoid arthritis (RA) is a prototypic chronic inflammatory disease with a debilitating course if untreated. A genetic predisposition for RA is known, and its occurrence is associated with the presence of autoantibodies in the serum and with environmental factors. It is unknown if smoking and overweight are contributory factors for developing RA in individuals with RA-specific autoantibodies in the serum.

Methods Fifty-five individuals at risk for developing RA, based on the presence of RA-specific autoantibodies in the serum, who never had any evidence of arthritis upon physical examination, were followed over time. Smoking was assessed as being never or ever smoker and body mass index as $<25$ (normal) or $\geq 25 \mathrm{~kg} / \mathrm{m}^{2}$ (overweight). Clinical endpoint was the occurrence of arthritis. Proportional hazard regression analysis was performed to investigate the potential of (combinations of) variables in predicting the onset of arthritis over time.

Results After a median follow up time of 13 (IQR 6-27) months, 15 individuals (27\%) developed arthritis. Smoking was associated with the development of arthritis (HR (95\% Cl): 9.6 (1.3 to 73.0); $p=0.029)$. Overweight was, independently of smoking, associated with arthritis (HR $(95 \% \mathrm{Cl}): 5.6(1.3$ to 25.0$) ; p=0.023)$. The overall arthritis risk of $28 \%$ after a median of 27 months follow up increased to $60 \%$ in individuals with a smoking history combined with overweight. Conclusions This is the first prospective study showing that smoking and overweight increase the risk of development of arthritis in a cohort of autoantibodypositive individuals at risk for developing RA. These results show the importance of life style factors in development of RA and should be critically evaluated in future clinical research aimed at disease prevention.

\section{INTRODUCTION}

Rheumatoid arthritis (RA) is an immune-mediated inflammatory disease characterised by inflammation of synovial joints, often resulting in degradation of articular cartilage and bone, ultimately leading to joint deformities. If untreated, RA leads to disability, loss of quality of life and work loss. RA causes premature death due to cardiovascular disease, analogous to diabetes mellitus ${ }^{1}$ and the impact of RA on costs for society is huge. ${ }^{2}$ The treatment of established RA is promising but expensive; therefore the need for prevention of RA, if possible, is obvious.

The aetiology of RA, though largely unknown, is considered multifactorial: a family history of RA and the presence of $\mathrm{MHC}$ class II genes ${ }^{3}$ and PTPN22 ${ }^{4}$ increase the susceptibility of RA; the presence of rheumatoid factor (RF) and anti-citrullinated protein-antibodies (ACPA) point to a contribution of autoimmunity mechanisms and environmental factors such as smoking ${ }^{5}$ and obesity, $^{6-8}$ and their interactions with genetic factors, have been considered important. ${ }^{9}$

Recent research has discovered that circulating autoantibodies $^{10-12}$ and increased acute phase reactants ${ }^{13}$ can precede the clinical onset of RA, but only a minority of individuals with RA-specific autoantibodies actually develops clinically manifest RA. ${ }^{14}$ However, the detection of these autoantibodies may define patients with systemic autoimmunity associated with RA without clinical evidence of arthritis, who are at risk of developing RA. ${ }^{15}$

In this prospective observational study the contributory role of the modifiable factors smoking and overweight on the development of arthritis in autoantibody-positive individuals at risk for developing RA was investigated.

\section{METHODS}

\section{Study subjects}

Individuals with either arthralgia and/or a positive family history for RA, but without any evidence of arthritis upon thorough physical examination, who were positive for IgM-RF and/or ACPA, were included in the study between June 2005 and August $2010 .{ }^{16}$ IgM-RF was measured using IgM-RF ELISA (Sanquin, Amsterdam, The Netherlands (upper limit of normal (ULN) $12.5 \mathrm{IU} / \mathrm{ml}$ )) until December 2009 and thereafter using IgM-RF ELISA (Hycor Biomedical, Indianapolis, Indiana, USA (ULN $49 \mathrm{IU} / \mathrm{ml})$ ). ACPA was measured using anti-CCP2 ELISA CCPlus (Eurodiagnostica, Nijmegen, the Netherlands (ULN $25 \mathrm{kAU} / \mathrm{l})$ ). These individuals were recruited via the outpatient clinic of the department of Clinical Immunology and Rheumatology of the AMC, Amsterdam, via the Rheumatology outpatient clinic of Reade, Amsterdam, or via testing family members of RA patients seen at the outpatient clinic or at public fairs across the Netherlands. The study was performed according to the principles of the Declaration of Helsinki, approved by the institutional review board, and all study subjects gave written informed consent.

\section{Study design}

At baseline, demographic parameters were obtained as well as environmental and clinical parameters. Overweight was defined as a body mass index 
(BMI) greater than or equal to $25 \mathrm{~kg} / \mathrm{m}^{2}$, according to the World Health Association (fact sheet $\mathrm{n}^{\circ} 311$ ). A detailed smoking history and smoking-status using number of 'pack years' was assessed, and smoking status was assigned as being a never smoker or an ever smoker. One pack year was defined as smoking 20 cigarettes per day for 1 year.

Study subjects were followed over time until January 2012. Annual study visits were performed. The development of arthritis, defined as a painful and swollen joint, was the endpoint of this study. In individuals with suspected arthritis an extra visit was performed, at which the presence of arthritis was confirmed by two independent investigators (MS and DG or MH and DG).

\section{Statistical analysis}

Differences between study groups in continuous parameters were analysed using $\mathrm{t}$ test or Mann-Whitney $\mathrm{U}$ test if appropriate. Categorical data were analysed using $\chi^{2}$ test.

Prediction analysis for arthritis-onset was performed using proportional hazard regression analysis (Cox-regression). Follow-up duration was defined as the time between inclusion in the cohort and the onset of clinically manifest arthritis, or between inclusion and January 2012 (censored). After univariate analysis, variables with $\mathrm{p}$ value $<0.2$ were selected for a multivariable analysis (forward and backward selection procedures). Meaningful statistical interactions were excluded upfront.

Statistical analysis was performed using PASW Statistics V.18 (SPSS Inc, Chicago, Illinois, USA).

\section{RESULTS}

\section{Cohort description}

Fifty-five autoantibody-positive individuals were included in the study (51 were referred to rheumatology outpatient clinics because of arthralgia, and four subjects without arthralgia were tested because of a positive family history for RA). Nineteen individuals were solely IgM-RF-positive, 22 were solely ACPA-positive and 14 were positive for both autoantibodies. Individuals were followed for a median duration of 27 (IQR: 14-47; range 1-75) months.

Fifteen of the 55 individuals (27\%) developed arthritis during follow up after a median duration of 13 (IQR: 6-27, range $0.5-47)$ months. Of the 15 patients who developed arthritis, 11 fulfilled the 2010 ACR/EULAR criteria for RA ${ }^{17} 18$ at arthritis onset and three were initially diagnosed as having undifferentiated arthritis but fulfilled the RA classification criteria later on (six fulfilled the 1987 ACR criteria for $\mathrm{RA}^{20}$ at arthritis onset and one later on). For clinical parameters at arthritis onset and baseline see online supplementary table S1. One patient who developed arthritis fulfilled the ACR classification criteria for osteoarthritis of the hand, ${ }^{19}$ but not for RA. This patient received non-steroidal anti-inflammatory drugs resulting in a permanent remission of clinical signs and symptoms of arthritis. Of the 14 patients ultimately fulfilling the classification criteria for RA, two did not receive disease-modifying antirheumatic drugs (DMARDs). One patient refused conventional treatment and used alternative medicines and the other patient refused treatment because of transient mono-arthritis for which he was closely monitored. Seven RA patients were treated with DMARD monotherapy, two with a combination of two DMARDs, one with a combination of a DMARD and anti-tumour necrosis factor (anti-TNF) therapy and one was included in a clinical trial evaluating the effects of anti-TNF therapy in early arthritis. After a median follow up of 18 (range 0-60) months three RA patients developed RA-erosions on $\mathrm{x}$-ray (the two patients who did not receive DMARD therapy and one patient treated with DMARD monotherapy).

\section{Increased percentage of smoking and overweight in autoantibody-positive individuals who develop arthritis after follow up}

The percentage of ever smokers and individuals with $\mathrm{BMI} \geq 25 \mathrm{~kg} / \mathrm{m}^{2}$ was higher in the group that developed arthritis than in the group that did not $(93 \%$ vs $53 \% ; \mathrm{p}=0.005$ for ever vs never smoking and $87 \%$ vs $45 \% ; \mathrm{p}=0.006$ for individuals with a $\mathrm{BMI} \geq 25 \mathrm{~kg} / \mathrm{m}^{2}$ vs those with a $\mathrm{BMI}<25 \mathrm{~kg} / \mathrm{m}^{2}$ ). The percentage of individuals who developed arthritis was 38\% in past smokers $(n=21)$ versus $43 \%$ in current smokers $(n=14)$ $(p=0.778$ for the comparison between past and current smokers), compared with $5 \%$ in the never smokers $(n=21)$ $(\mathrm{p}=0.019$ for the comparison between never smokers and past/ current smokers). IgM-RF- and ACPA-status and levels were comparable between individuals who developed arthritis versus those who did not (see table 1).

\section{Smoking and overweight are predictors for the development of clinically manifest arthritis}

In the proportional hazard regression analysis, 'ever smoking' was associated with the development of clinically manifest arthritis (HR (95\% CI): $9.6(1.3$ to 73.0$) ; \mathrm{p}=0.029)$ (table 2).

Only one individual who never smoked developed arthritis over time. There was no difference between past and current smokers with regard to the onset of arthritis $(p=0.677)$. The relationship between smoking and the development of arthritis was not confounded by any of the other variables measured (data not shown). Besides smoking, BMI $\geq 25 \mathrm{~kg} / \mathrm{m}^{2}$ at baseline

Table 1 Baseline demographic and clinical parameters

\begin{tabular}{|c|c|c|c|}
\hline Characteristic & $\begin{array}{l}\text { No arthritis } \\
\text { developed } \\
\mathrm{N}=40^{*}\end{array}$ & $\begin{array}{l}\text { Arthritis } \\
\text { developed } \\
\mathrm{N}=15\end{array}$ & $\begin{array}{l}p \\
\text { Value }\end{array}$ \\
\hline Sex, female (n (\%)) & $28(70)$ & $9(60)$ & 0.481 \\
\hline Age (years) (mean (SD)) & $44(12)$ & $47(8)$ & 0.471 \\
\hline $\begin{array}{l}\text { Smoking history, evert (n } \\
(\%) \text { ) }\end{array}$ & $21(53)$ & $14(93)$ & 0.005 \\
\hline Pack years $\ddagger$ (median (IQR)) & $10(4-20)$ & $15(10-24)$ & 0.129 \\
\hline $\mathrm{BMI} \geq 25, \mathrm{~kg} / \mathrm{m}^{2}(\mathrm{n}(\%))$ & $18(45)$ & $13(87)$ & 0.006 \\
\hline IgM-RF positive (n (\%)) & $24(57)$ & $9(60)$ & 0.847 \\
\hline $\begin{array}{l}\text { IgM-RF level low positive } \\
(\mathrm{n}(\%)) \S\end{array}$ & $15(62)$ & $4(44)$ & 0.3509 \\
\hline $\begin{array}{l}\text { IgM-RF level high positive } \\
(\mathrm{n}(\%)) \S\end{array}$ & $9(38)$ & $5(56)$ & \\
\hline ACPA positive (n (\%)) & $24(60)$ & $12(80)$ & 0.165 \\
\hline $\begin{array}{l}\text { ACPA level§ (kAU/L) } \\
\text { (median (IQR)) }\end{array}$ & $465.5(69.5-1229.8)$ & $\begin{array}{l}452.0 \\
(103.0-2518.8)\end{array}$ & 0.585 \\
\hline $\begin{array}{l}\text { IgM-RF and ACPA } \\
\text { both pos. (n (\%)) }\end{array}$ & $8(20)$ & $6(40)$ & 0.129 \\
\hline \multicolumn{4}{|c|}{$\begin{array}{l}\text { p Values }<0.05 \text { in bold. } \\
\text { * Seven individuals have been at risk for arthritis development for a shorter period of } \\
\text { time: two patients have started with hydroxychloroquine for arthralgias, and two with } \\
\text { anti-TNF therapy because of a diagnosis of ankylosing spondylitis }(n=1) \text { or Crohn's } \\
\text { disease }(n=1) \text {. Three individuals were lost to follow up after some time. } \\
\text { †Smoking history: never smoked: } 0 \text { pack-years; ever smoked: }>0 \text { pack-years. } \\
\text { ¥Only in smokers. } \\
\text { §Only in positive individuals: low positive: } \leq 3 \text { times upper limit of normal (ULN), high } \\
\left.\text { positive: }>3 \text { times ULN (according to the } 2010 \text { ACR/EULAR criteria for RA }{ }^{17}{ }^{18}\right) \text {. } \\
\text { qUsing } \chi^{2} \text { test for frequencies of low and high positivity of IgM-RF in the two } \\
\text { outcome groups. } \\
\text { ACPA, anti-citrullinated protein antibodies; BMI, body mass index; IgM-RF, } \\
\text { IgM-rheumatoid factor; RA, rheumatoid arthritis. }\end{array}$} \\
\hline
\end{tabular}


Table 2 Multivariable regression analysis for smoking and body mass index (BMI)

\begin{tabular}{lll}
\hline Variables in model & HR $(95 \% \mathrm{Cl})$ & p Value \\
\hline $\begin{array}{l}\text { Model } 1 \\
\quad \text { Smoking (ever vs never) }\end{array}$ & $9.6(1.3$ to 72.9$)$ & 0.029 \\
$\begin{array}{l}\text { Model } 2 \\
\left.\text { BMl ( } \geq 25 \text { vs }<25 \mathrm{~kg} / \mathrm{m}^{2}\right)\end{array}$ & $5.6(1.3$ to 25.0$)$ & 0.023 \\
Model 3 & & \\
$\quad$ Smoking (ever vs never) & $8.2(1.1$ to 62.6$)$ & 0.042 \\
BMI ( $\geq 25$ vs $\left.<25 \mathrm{~kg} / \mathrm{m}^{2}\right)$ & $4.8(1.1$ to 21.4$)$ & 0.039 \\
\hline
\end{tabular}

was associated with the development of arthritis (HR (95\% CI): $5.6(1.3$ to 25.0$) ; p=0.023)$. In the proportional hazard regression analysis smoking and BMI independently conferred an increased risk on clinically manifest arthritis. Of importance, BMI did not significantly correlate with smoking status $(p=0.472)$ and within the group of ever smokers BMI was significantly higher in the subgroup of individuals who developed arthritis compared with the group who did not (28.1 (27.3-34.0) (median (IQR)) vs 24.6 (21.7-28.7): $\mathrm{p}=0.010)$.

In this cohort IgM-RF positivity was not associated with the development of arthritis, and ACPA-positivity showed a trend towards a predictive association (HR (95\% CI): 2.7 (0.8 to 9.7); $\mathrm{p}=0.119)$, but did not have predictive value over and above smoking and/or BMI. Of note, subjects were selected based on being positive for IgM-RF and/or ACPA, which limits the predictive interpretability of IgM-RF and ACPA in this cohort. Other clinical parameters were not associated with the development of arthritis (data not shown).

When combining smoking and BMI the frequency of arthritis development was significantly higher in ever smokers with $\mathrm{BMI} \geq 25 \mathrm{~kg} / \mathrm{m}^{2}$ compared with the other three categories $(\mathrm{p}=0.001)$ (see table 3$)$.

In conclusion, when performing proportional hazard regression analysis the combination of being an ever smoker with $\mathrm{BMI} \geq 25 \mathrm{~kg} / \mathrm{m}^{2}$ resulted in an increase of the risk for development of clinically manifest arthritis from $28 \%$ to $60 \%$ after median follow up in this cohort of 27 months (figure 1).

\section{DISCUSSION}

The results presented here show that modifiable lifestyle factors such as smoking and overweight may importantly contribute to the onset of clinically manifest arthritis in autoantibody-positive individuals at risk of developing RA.

The first important observation in this prospective study is the association between smoking and development of arthritis.

Table 3 Frequency table for arthritis development in subgroups of smoking and body mass index (BMI)

\begin{tabular}{|c|c|c|c|}
\hline \multicolumn{2}{|c|}{ Never smoker } & \multicolumn{2}{|c|}{ Ever smoker } \\
\hline $\begin{array}{l}\mathrm{BMI}<25 \\
\mathrm{~kg} / \mathrm{m}^{2} \\
(\mathrm{~N}=10)\end{array}$ & $\begin{array}{l}\mathrm{BMI} \geq 25 \\
\mathrm{~kg} / \mathrm{m}^{2} \\
(\mathrm{~N}=10)\end{array}$ & $\begin{array}{l}\mathrm{BMI}<25 \\
\mathrm{~kg} / \mathrm{m}^{2} \\
(\mathrm{~N}=14)\end{array}$ & $\begin{array}{l}\mathrm{BMI} \geq 25 \\
\mathrm{~kg} / \mathrm{m}^{2} \\
(\mathrm{~N}=21)\end{array}$ \\
\hline $40(24-71)$ & $28(17-51)$ & $23(17-41)$ & $26(9-42)$ \\
\hline $0(0)$ & $1(10)$ & 2 (14) & $12(57)$ \\
\hline
\end{tabular}

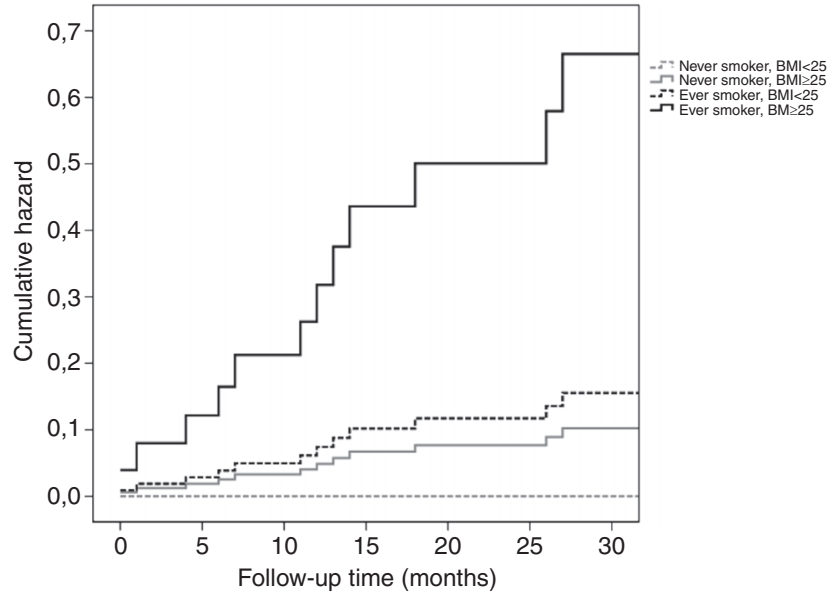

Figure 1 Cumulative hazard for arthritis development in subgroups of smoking and body mass index. X-axis: follow up time in months; Y-axis: cumulative hazard for arthritis development.

Smoking has recently been suggested to be a risk factor for developing RA, ${ }^{5}$ but so far only association studies have been performed. Our study is the first analysing the impact of smoking on the development of arthritis by prospectively following individuals with RA-specific autoantibodies without signs of arthritis who are at risk of developing the disease.

Recent studies have suggested that the lung may be an early site of RA-related auto-immunity, supposedly by the effect of smoking on the citrullination of peptides. ${ }^{20}$ Interestingly, in a comparable cohort of individuals at risk for RA with elevated ACPA levels and greater than or equal to 2 RF isotypes without arthritis airway abnormalities were observed similar to those found in RA patients, and significantly more than in autoantibody-negative controls. ${ }^{21}$

In contrast to what has been suggested previously, ${ }^{22}$ the high risk for smoking on arthritis development was not dependent on ACPA-status in our study. In addition, we were unable to define ACPA-status itself as risk factor, in contrast to what was observed in another cohort studying 147 autoantibody-positive individuals without clinically apparent arthritis. ${ }^{14}$ This is likely due to the relatively small number of study participants and differences in inclusion criteria between the current study and the previous. Second, overweight appeared to be a predicting factor for arthritis onset, independently of smoking. Thus far, the results of association studies of overweight/obesity and RA have been variable, ${ }^{6-8} 23-26$ with different results for ACPA positive and negative $\mathrm{RA}^{25} 26$ and males and females. ${ }^{6}{ }^{26}$ More in general, an association between obesity and inflammation has been clearly demonstrated. ${ }^{27}$ Adiposity is characterised by adipocyte hypertrophy, leading to release of stress signals, such as endoplasmic reticulum stress, ${ }^{28}$ and production of reactive oxygen species. As a result, inflammatory pathways are activated and inflammatory cells, such as macrophages and CD8 + T-cells, recruited into the adipose tissue. Adiposity is associated with increased production of pro-inflammatory adipocytokines, including leptin, $\mathrm{TNF} \alpha$, interleukin 1 (IL-1), IL-6 and monocyte chemotactic protein 1 (MCP-1), and decreased production of the anti-inflammatory adiponectin. How this systemic proinflammatory state would lead to inflammation in the joint, needs to be elucidated. It is also possible that proinflammatory activity of adipose tissue in the synovial sublining of the joint might be involved. Previous work has shown that articular adipose tissue obtained from RA patients produced pro- and anti-inflammatory 
(adipo-) cytokines upon activation, with stimulating effects on fibroblast-like synoviocytes. $^{29}$

In our cohort the overall arthritis risk of $28 \%$ after a median of 27 months follow up increased to $60 \%$ in individuals with a smoking history combined with overweight. This observation was made in a relatively small cohort, suggesting that the effects of smoking and overweight are strong. In comparison, the risk for developing arthritis in never smokers with normal weight was only $2 \%$, showing that life style modification might have important consequences for arthritis development in RA-prone individuals.

The importance of our findings is emphasised by the increased incidence of RA over the last decades, which cannot be explained by genetic factors, but is most likely influenced by environmental factors. ${ }^{8}$ Although this study does not demonstrate that smoking cessation and/or weight reduction are effective in reducing the risk of RA, it is obvious that smoking and increased body weight are inherently modifiable lifestyle factors which are also important in other diseases and that modification leads to decreased health risks in general. An intensive prevention programme in Finland aiming at dietary changes and smoking cessation has resulted in long-term prevention of cardiovascular diseases ${ }^{30}$ which was accompanied by a similar decline in the incidence of RA. ${ }^{31}$ Such programmes may contribute to the prevention of RA and related co-morbidities and to a decreased socio-economic burden.

The results of this study, if confirmed in larger, independent cohorts, may also help to better define a population at high risk of developing RA based on the presence of RA-specific autoantibodies, smoking history, and overweight. Improved prediction models may facilitate studies aimed at prevention of RA by targeted intervention during the preclinical phase. ${ }^{32}$

A limitation of this study is the relatively small sample size. The effects observed in our cohort provide the rationale for larger studies in independent cohorts to validate the results presented here. Currently we are unable to determine whether smoking and obesity are crucial for development of autoantibody positive RA in most patients, or whether these factors merely advance the onset of arthritis. We will continue to follow these individuals to address this issue over time.

It should also be noted that we chose to define the presence of arthritis based on clinical assessment by two experienced investigators rather than by imaging, consistent with clinical practice and evaluation in most clinical trials. Of note, the implications of synovitis shown by ultrasound or MRI in the absence of clinical evidence of arthritis are currently still incompletely understood.

In conclusion, the results presented here suggest that preventable factors, such as smoking and overweight, may increase the risk of developing RA in RF and/or ACPA positive individuals.

\footnotetext{
Acknowledgements We thank our study subjects for participating in the study. Contributors MJHH was involved in study design, data collection, data analysis, interpretation of data and preparing the manuscript; RBML was involved in data analysis, interpretation of data and preparing the manuscript; MGHS was involved in study design, data collection, interpretation of data and preparing the manuscript; DS was involved in data collection and revising the manuscript critically; LGMB was involved in data analysis, interpretation of data and preparing the manuscript; DMG was involved in study design, data collection, interpretation of data and preparing the manuscript; PPT was involved in study design, data collection, interpretation of data and preparing the manuscript.
}

Funding The study was supported by the Dutch Arthritis Foundation (grant 06-1-303 and 11-1-407), the Netherlands Organisation for Health Research and Development (ZonMw) grant 200310003, the IMI EU funded project BeTheCure $n^{\circ}$ 115142 and FP7 Euro-TEAM consortium n 305549.

Competing interests None.
Ethics approval The study was approved by the institutional review board of the Academic Medical Center, Amsterdam, The Netherlands.

Provenance and peer review Not commissioned; externally peer reviewed.

Data sharing statement Data of our research article are available upon request. Additional data of this cohort are expected to be published in the future.

Correction notice This article has been corrected since it was published Online First. Grammatical errors have been corrected.

Open Access This is an Open Access article distributed in accordance with the Creative Commons Attribution Non Commercial (CC BY-NC 3.0) license, which permits others to distribute, remix, adapt, build upon this work non-commercially, and license their derivative works on different terms, provided the original work is properly cited and the use is non-commercial. See: http://creativecommons.org/ licenses/by-nc/3.0/

\section{REFERENCES}

1 Bisoendial RJ, Stroes ES, Tak PP. Critical determinants of cardiovascular risk in rheumatoid arthritis. Curr Pharm Des 2011;17:21-6.

2 Boonen A, Severens JL. The burden of illness of rheumatoid arthritis. Clin Rheumatol 2011;30(Suppl 1):S3-8.

3 Stastny P. Association of the B-cell alloantigen DRw4 with rheumatoid arthritis. N Engl J Med 1978;298:869-71.

4 Begovich $A B$, Carlton VE, Honigberg LA, et al. A missense single-nucleotide polymorphism in a gene encoding a protein tyrosine phosphatase (PTPN22) is associated with rheumatoid arthritis. Am J Hum Genet 2004;75:330-7.

5 Sugiyama D, Nishimura K, Tamaki K, et al. Impact of smoking as a risk factor for developing rheumatoid arthritis: a meta-analysis of observational studies. Ann Rheum Dis 2010;69:70-81.

6 Symmons DP, Bankhead CR, Harrison BJ, et al. Blood transfusion, smoking, and obesity as risk factors for the development of rheumatoid arthritis: results from a primary care-based incident case-control study in Norfolk, England. Arthritis Rheum 1997;40:1955-61.

7 Voigt LF, Koepsell TD, Nelson JL, et al. Smoking, obesity, alcohol consumption, and the risk of rheumatoid arthritis. Epidemiology 1994;5:525-32.

8 Crowson CS, Matteson EL, Davis JM III, et al. Obesity fuels the upsurge in rheumatoid arthritis. Arthritis Care Res (Hoboken) Published Online First: 18 Apr 2012. doi:10.1002/acr.21660.

9 Scott IC, Steer S, Lewis CM, et al. Precipitating and perpetuating factors of rheumatoid arthritis immunopathology: linking the triad of genetic predisposition, environmental risk factors and autoimmunity to disease pathogenesis. Best Pract Res Clin Rheumatol 2011;25:447-68

10 Aho K, Heliovaara M, Maatela J, et al. Rheumatoid factors antedating clinical rheumatoid arthritis. J Rheumatol 1991;18:1282-4.

11 Nielen MM, van SD, Reesink HW, et al. Specific autoantibodies precede the symptoms of rheumatoid arthritis: a study of serial measurements in blood donors. Arthritis Rheum 2004;50:380-6.

12 Rantapaa-Dahlqvist S, de Jong BA, Berglin E, et al. Antibodies against cyclic citrullinated peptide and IgA rheumatoid factor predict the development of rheumatoid arthritis. Arthritis Rheum 2003;48:2741-9.

13 Nielen MM, van SD, Reesink HW, et al. Increased levels of C-reactive protein in serum from blood donors before the onset of rheumatoid arthritis. Arthritis Rheum 2004;50:2423-7.

14 Bos WH, Wolbink GJ, Boers $M$, et al. Arthritis development in patients with arthralgia is strongly associated with anti-citrullinated protein antibody status: a prospective cohort study. Ann Rheum Dis 2010;69:490-4.

15 Gerlag DM, Raza K, van Baarsen LG, et al. EULAR recommendations for terminology and research in individuals at risk of rheumatoid arthritis: report from the Study Group for Risk Factors for Rheumatoid Arthritis. Ann Rheum Dis 2012;71:638-41.

16 van de Sande MG, de Hair MJ, van der Leij C, et al. Different stages of rheumatoid arthritis: features of the synovium in the preclinical phase. Ann Rheum Dis 2011;70:772-7

17 Aletaha D, Neogi T, Silman AJ, et al. 2010 Rheumatoid arthritis classification criteria: an American College of Rheumatology/European League Against Rheumatism collaborative initiative. Arthritis Rheum 2010;62:2569-81.

18 Aletaha D, Neogi T, Silman AJ, et al. 2010 rheumatoid arthritis classification criteria: an American College of Rheumatology/European League Against Rheumatism collaborative initiative. Ann Rheum Dis 2010;69:1580-8.

19 Altman R, Alarcon G, Appelrouth D, et al. The American College of Rheumatology criteria for the classification and reporting of osteoarthritis of the hand. Arthritis Rheum 1990;33:1601-10.

20 Klareskog L, Malmstrom V, Lundberg K, et al. Smoking, citrullination and genetic variability in the immunopathogenesis of rheumatoid arthritis. Semin Immunol 2011;23:92-8.

21 Demoruelle MK, Weisman MH, Simonian PL, et al. Brief report: airways abnormalities and rheumatoid arthritis-related autoantibodies in subjects without arthritis: early injury or initiating site of autoimmunity? Arthritis Rheum 2012;64:1756-61. 
22 Lundstrom E, Kallberg $\mathrm{H}$, Alfredsson L, et al. Gene-environment interaction between the DRB1 shared epitope and smoking in the risk of anti-citrullinated protein antibody-positive rheumatoid arthritis: all alleles are important. Arthritis Rheum 2009;60:1597-603.

23 Cerhan JR, Saag KG, Criswell LA, et al. Blood transfusion, alcohol use, and anthropometric risk factors for rheumatoid arthritis in older women. J Rheumatol 2002;29:246-54

24 Hernandez AM, Liang MH, Willett WC, et al. Reproductive factors, smoking, and the risk for rheumatoid arthritis. Epidemio/ 1990;1:285-91.

25 Pedersen $\mathrm{M}$, Jacobsen $\mathrm{S}$, Klarlund $\mathrm{M}$, et al. Environmental risk factors differ between rheumatoid arthritis with and without auto-antibodies against cyclic citrullinated peptides. Arthritis Res Ther 2006;8:R133.

26 Wesley A, Bengtsson C, Elkan AC, et al. Association between overweight, obesity, ACPA positive and ACPA negative Rheumatoid Arthritis-, results from the EIRA case-control study. Arthritis Care Res (Hoboken) Published Online First: 5 Jun 2012. doi:10.1002/acr.21749.
27 Ouchi N, Parker JL, Lugus JJ, et al. Adipokines in inflammation and metabolic disease. Nat Rev Immunol 2011;11:85-97.

28 Guri AJ, Bassaganya-Riera J. Systemic effects of white adipose tissue dysregulation and obesity-related inflammation. Obesity (Silver Spring) 2011;19: 689-700.

29 Kontny E, Plebanczyk M, Lisowska B, et al. Comparison of rheumatoid articular adipose and synovial tissue reactivity to proinflammatory stimuli: contribution to adipocytokine network. Ann Rheum Dis 2012;71:262-7.

30 Puska P, Vartiainen E, Tuomilehto J, et al. Changes in premature deaths in Finland: successful long-term prevention of cardiovascular diseases. Bull World Health Organ 1998;76:419-25.

31 Kaipiainen-Seppanen 0, Kautiainen $\mathrm{H}$. Declining trend in the incidence of rheumatoid factor-positive rheumatoid arthritis in Finland 1980-2000. J Rheumatol 2006;33:2132-8.

32 Tak PP. Are we ready to change the pace of arthritis treatment? Treating pre-arthritis and very early arthritis. Acta Reumatol Port 2011;36:8-9. 